\title{
Electoral Strategy in Geographic Space: Accounting for Spatial Proximity in District-Level Party Competition
}

\author{
Joshua D. Potter \\ Assistant Professor \\ Louisiana State University \\ jpotter@lsu.edu
}

\author{
Santiago Olivella \\ Assistant Professor \\ The University of Miami \\ olivella@miami.edu
}

\begin{abstract}
How does a political party choose where to field candidates or party lists? Traditional models of party competition mainly focus on strategy: parties enter districts where they believe they could win many votes or seats. These strategic considerations are typically couched in terms of ideological positioning and the mechanics of the vote-to-seat translation at the district level. However, parties' entry decisions are also subject to geographical limitations and no prior study has explored the extent to which geography limits strategic entry at the district level. In this paper, we explore the severity of those limitations by modeling strategic and geographic factors side-by-side. In so doing, we find that geography limits parties' entry decisions, specifically by dampening the effects of strategic incentives to enter in geographically distant districts. We utilize a highly detailed district-level database of seven multimember European countries and tens of thousands of party entry decisions across these districts. ${ }^{1}$
\end{abstract}

Key words: political parties, electoral geography, electoral competition

Word count: about 10,000 including text, tables, and citations

\footnotetext{
${ }^{1}$ We would like to thank Brian Crisp, Margit Tavits, Guillermo Rosas, Scott Morgenstern, Dawn Brancati, Sunita Parikh, Randy Calvert, Jacob Montgomery, Jim Garand, Dave Sobeck, Bill Clark, Chris Mann, Zeynep Somer-Topcu, Liz Zechmeister, Diana O’Brien, Dennis Chong, Lee Epstein, Christian Grose, Chris Weber, Kyle Beardsley, and Chad Westerland for many helpful comments on earlier and related drafts of this paper. Special thanks go to Dawn Brancati for providing us with an excellent data source upon which to ground the project. Joshua Potter acknowledges financial support for this research from the National Science Foundation (Grant SES-1124460). Corresponding author email: jpotter@lsu.edu
} 


\title{
Electoral Strategy in Geographic Space: Accounting for Spatial Proximity in District-Level Party Competition
}

\author{
Joshua D. Potter \\ Assistant Professor \\ Louisiana State University \\ Santiago Olivella \\ Assistant Professor \\ The University of Miami
}

\section{Forthcoming in Electoral Studies}

\begin{abstract}
How does a political party choose where to field candidates or party lists? Traditional models of party competition mainly focus on strategy: parties enter districts where they believe they could win many votes or seats. These strategic considerations are typically couched in terms of ideological positioning and the mechanics of the vote-to-seat translation at the district level. However, parties' entry decisions are also subject to geographical limitations and no prior study has explored the extent to which geography limits strategic entry at the district level. In this paper, we explore the severity of those limitations by modeling strategic and geographic factors side-by-side. In so doing, we find that geography limits parties' entry decisions, specifically by dampening the effects of strategic incentives to enter in geographically distant districts. We utilize a highly detailed district-level database of seven multimember European countries and tens of thousands of party entry decisions across these districts. ${ }^{1}$
\end{abstract}

\footnotetext{
${ }^{1}$ We would like to thank Brian Crisp, Margit Tavits, Guillermo Rosas, Scott Morgenstern, Dawn Brancati, Sunita Parikh, Randy Calvert, Jacob Montgomery, Jim Garand, Dave Sobeck, Bill Clark, Chris Mann, Johanna Dunaway, Zeynep Somer-Topcu, Liz Zechmeister, Diana O'Brien, Dennis Chong, Lee Epstein, Christian Grose, Chris Weber, Kyle Beardsley, and Chad Westerland for many helpful comments on earlier and related drafts of this paper. Special thanks go to Dawn Brancati for providing us with an excellent data source upon which to ground the project. Joshua Potter acknowledges financial support for this research from the National Science Foundation (Grant SES-1124460). Corresponding author email: jpotter@lsu.edu
} 


\section{INTRODUCTION}

Given that a party chooses to contest some - but not all - districts in an election, how can we explain where it chooses to enter? Because parties that universally contest all districts in a country are comparatively rare, this is an important question that affects many parties around the world. For a number of reasons, these parties assess their electoral prospects differently across different electoral constituencies and ultimately conclude that some constituencies are simply not worth the time, resources, and effort of fielding a candidate or a list of candidates. Instead of contesting all districts, they forgo potential opportunities in some districts in order to more specifically chase opportunities in others.

Empirically, these parties tend to be the norm rather than the exception. A recent survey of elections in several democratic countries around the world since 1945 indicates that more than $75 \%$ of parties enter electoral districts selectively rather than uniformly. ${ }^{2}$ That is, roughly three-fourths of political parties in the world's democracies elect not to give every voter in the country the opportunity to cast a ballot in their favor. Furthermore, these parties are not electorally insignificant. On average, these parties entered a nontrivial share of a country's districts (about 25\%) and, more importantly, these parties garnered more than $60 \%$ of all votes cast across all elections in the data set.

Previous comparative studies of electoral politics have not yet addressed the question of district-level selective entry into electoral competition by political parties, let alone wrestled with its implications for literatures ranging from party nationalization to models of vote choice and collective preference aggregation. ${ }^{3}$ When not all voters have access to all parties

\footnotetext{
2 Figures based on authors' original calculations across 3,919 party-election observations taken from data downloaded from the Global Elections Database (Brancati, 2014). These data include parties from more than 30 democratic countries, including the subset of countries we focus on in the present study. This data will be described in greater detail below.

${ }^{3}$ Studies of the emergence of new parties (Kitschelt, 1988; Meguid, 2005; Mudde, 2007), for example, or of parties with platforms grounded in regional social cleavages (Chhibber and Kollman, 2004; Brancati, 2008),
} 
on their ballots, then it becomes difficult to talk about, say, the "homogeneity" of a party's support among voters across electoral districts (Caramani, 2000; Jones and Mainwaring, 2003) or the choices that voters make on election day (Jackson, 2002; Katz and King, 1999), or even the meaningfulness of social choice in an unbiased fashion (Plott, 1973; Chernoff, 1954). Accounting for why and where some parties will be absent from voters' ballots should allow for a deeper understanding of these national-level concepts which are so vital to the field of electoral studies.

Several empirical obstacles stand in the way, however, of such an accounting. First, although many of the factors long thought to inform entry decisions operate at the district level, most studies empirically focus on the aggregate, national level (Lago and Martinez, 2010; Selb and Pituctin, 2010). Second, although characteristics of voter and party elite preferences and strategies can reasonably be expected to affect entry choices, measuring such characteristics at the district level has proven problematic - an issue that is particularly exacerbated in the large- $n$ comparative context. Finally, empirical work on entry decisions often fails to account for potential dependencies in the data, especially dependencies introduced by geographic proximity between electoral districts (Rodden, 2010; Selb and Pituctin, 2010). In this paper, our aim is to address all these concerns without sacrificing the advantages of a large- $n$ and cross-national empirical study. Specifically, our contributions are threefold.

First, we offer an omnibus empirical test of the many potential determinants of selective party entry at the district level. We review a set of straightforward - but not trivial intuitions derived from prior literature about what types of strategic considerations might drive patterns of entry. For example, parties may select those districts where they perceive

only address this question indirectly and are unable to provide systematic explanations that operate across all countries and time periods. While previous studies of resource barriers to new party emergence (Harmel and Robertson, 1985; Hug, 2001) tell us something about the impediments that parties face in deciding whether or not to contest an election at the national level, they have nothing to say on a district-by-district basis at the intranational level. Even outside of comparative studies, formal theoretical literature in the American context tends to develop logics that are problematic in multiparty settings (Callander, 2005). 
themselves to be electorally viable. But electoral "viability" is a complicated concept to disaggregate and it hinges not only on electoral math, but also a party's assessment of its fit with the representational needs of voters in a district. Such issues as ideological affinity and demographic fit may come to bear on whether or not a party enters this particular district at the expense of some other district and we address each of these considerations in turn.

Secondly, and perhaps most importantly, we are able to demonstrate for the first time the extent to which the geographic arrangement of electoral districts modifies the above considerations. As any interview with a party operative would reveal, abstract theoretical concerns are certainly curbed by simpler logistical considerations: moving campaign resources and volunteers between districts, covering districts that exist in the same media market, and so on. These considerations would imply that, all else being equal, parties would much rather enter districts in close proximity to districts where they have already deployed resources than districts where such resources are distant. Third, we conduct all of our analyses under the umbrella of a multilevel modeling strategy. As opposed to some prior research that does not allow for flexibility at different levels of analysis, our research design pairs party-level attributes with district-level attributes and makes no a priori restrictive assumptions about how different parties might view the same district. Instead, we explicitly model the ways in which the same district can assume different meanings for different parties based on how that district fits into each party's unique electoral context.

Ultimately, we argue that failing to account for the geographic dimension in parties' entry decisions can lead researchers to overstate the strength of findings related to the more straightforward strategic story. To be sure, the "cost" of winning a seat, the ease of crossing that threshold, and ideological and demographic affinities are all salient and predictable determinants of selective entry. But even more, we demonstrate that these things matter especially in proximate districts, but almost not at all in more distant districts. We test our theory on hundreds of parties and districts drawn from seven proportional representation (PR) countries across Western and Eastern Europe. By focusing on PR systems, we have 
constructed for ourselves a difficult environment in which to return support for our geographical argument: the conventional wisdom holds that, relative to single-member district (SMD) systems, party competition and representation in PR systems is substantially less predicated on geography. The fact that we return such dramatic evidence in favor of geography's role indicates that the effect is expected to be even stronger both in SMD countries as well as in PR countries with smaller average district magnitudes.

\section{THE DETERMINANTS OF PARTY COMPETITION}

Even in party systems where several party offerings are universal, many parties still contest elections by entering a subset of districts selectively - whether because they are resourcestrapped, new, niche, regional, or simply en route to broader patterns of competition (Blais et al., 2011; Morgenstern and Vazquez-D'Elia, 2007). Explaining these parties' decisions, however, requires disaggregating the discussion about strategic entry from a national perspective to a district perspective (Selb and Pituctin, 2010). Prior research on party entry cast at the national level concludes that the more salient determinants of entry are things that simply do not vary across districts (Lago and Martinez, 2010). If political elites determine that their party's electoral prospects differ across districts, then we need to seek out determinants of these elite assessments that vary at the district level.

Prior literature has offered several types of motivations that might drive a selectively entering party to field a candidate or list of candidates in one electoral district at the expense of doing so in some other. In this paper, we focus on two major sets of motivations, while also controlling for additional determinants. The first motivation is geography both in its own right and in interaction with other types of motivations. That is to say, parties might opt for entering districts that are clustered in close proximity to one another in order to make use of organizational returns to scale with on-the-ground resource investments. Parties might also acutely respond to other strategic incentives in more geographically proximate - rather than in more distant - electoral districts. The second major motivation is strategy or the 
extent to which a party believes it can win substantial votes - and at least one seat - in an electoral district. Strategic considerations include both supply-side factors, such as the cost of winning a seat and the crowdedness of the district as well as demand-side factors such as vote volatility and wasted votes. In what follows, we review theoretical expectations from prior literature about both geography and strategy. We conclude this literature review by briefly noting the importance of controlling for the ideological and demographic makeup of individual districts when testing for the effects of geography and strategy. ${ }^{4}$

\subsection{Geography as both Determinant and Mediator}

Beginning with Tobler's first law of geography, the field of human geography has long recognized that the ways in which electoral constituencies are situated in geographic space can impact both electoral outcomes and party strategies (Tobler, 1970; Taylor and Gudgin, 1976; Johnston and Hughes, 2008; Rodden, 2010). Our specific application of this logic to the question of party entry points to two reasons why geography should influence entry decisions. First, geographic proximity between districts allows parties to make use of returns to scale on on-the-ground campaign and infrastructural investments. ${ }^{5}$ In this sense, geographic proximity additively increases the probability that a party will enter an electoral district: as an unentered district moves closer to another entered district, a party is more likely to enter

${ }^{4}$ We grant at the outset of the discussion that there are actually three types of decisions selectively entering parties undertake on a district-by-district basis: (1) whether to enter a new district for the first time; (2) whether to re-enter a previously entered district; and (3) whether to exit a previously entered district. Our review of the literature and empirical analysis do not differentiate between decisions of type (1) and (2) and we have very little to say about (3). We do not think that the same party would have a theoretically justifiable reason to prioritize different types of considerations across (1) and (2); to do so would posit a different utility function for the party across elections or perhaps even across districts within the same election. Empirically, we do not possess enough leverage to adequately model decisions of type (3) because they are exceedingly rare in our database.

${ }^{5}$ Throughout the ensuing discussion, we use "proximity" to indicate the distance between a previously unentered district and a previously entered district. 
the unentered district. Second, geographic proximity between districts should amplify the effects of many of the strategic variables we discuss below. In this sense, geographic proximity mediates the influence of various strategic, ideological, and demographic considerations; for example, a strategically favorable environment in a proximate district is made all the more tempting by virtue of its proximity to a previously entered district.

Our justification for the additive effect of geography on entry decisions rests in the burgeoning literature on the role of local-level party organization and campaign management. Gimpel, Lee and Kaminski (2006), for example, find that parties' donor support bases are often clustered in geographical space and, in some cases, are even more spatially consolidated than those districts from which parties chiefly draw their electoral support. Huckfeldt and Sprague (1992) and Carty and Eagles (1999) demonstrate that parties target localities of proximately located voters and think about their efforts in terms of adjacent neighborhoods and districts. The strategic viability of these exercises is evident, as recently demonstrated by Tavits (2012), who argues that highly organized parties (measured by indicators such as number and strength of branch offices) tend to fare better on election day. Parties clearly have an incentive to pay attention to organization, and coordinating their organizational efforts becomes more complicated and expensive as they diffuse across the country.

In general, selectively contesting districts which are spatially concentrated - and passing on opportunities to contest districts which are further afield - can be expected to bring returns to scale on resource expenditures. For example, districts which are located in closer proximity to one another might be reached through the same media markets, thereby allowing parties to make efficient use of broadcast and advertising resources (Campbell, Alford and Henry, 1984; Althaus and Trautman, 2008). It is also easier for parties to move party volunteers and professional staff between proximately-located districts and both of these entities have been found to be exceedingly helpful for parties' electoral prospects (Scarrow, 1994; Mudde, 2007). Closer organizational outposts should result in greater fluidity, ease of movement, and shortened response time for parties. Overall, then, there is enough reason to 
believe that geographic proximity should additively drive up the probability of party entry at the district level. Thus, we posit the following:

H1: Districts located in close geographic proximity to other districts entered by a given party will more likely be entered by that party.

Pushing further, we argue that geography mediates parties' other electoral concerns. As we argue below, parties pay attention to many attributes of electoral districts when determining where to field their candidates, but the same attribute means different things in different contexts. A party operative might, after all, be able to identify a constituency where her platform would potentially resonate with voters, but nevertheless take a pass on the opportunity if the district is much too far away from her on-the-ground campaign resources. For this reason, we argue that proximity has a distinctive mediating effect, because space influences a party's relative ability to draw on similarities for electoral gain by exploiting cost-effectiveness in the creation and maintenance of electoral infrastructures. Hence, a party will be expected to forgo fielding candidates in districts that are rather far afield of its current battery of campaign offices and electoral infrastructure. Two otherwise exceedingly similar districts - in strategic and sociodemographic terms - will present different opportunities for the same party if one is more proximate and the other more distant. Thus, we hypothesize an additional, mediating effect of geography:

H2: Geographic space mediates the role of strategic determinants of the probability of entry. That is, these relationships are made stronger in proximate districts and weakened in distant districts.

\subsection{Strategic Considerations}

Although different parties contest elections with different motivations, their aspirations can usually be best realized by winning or by coming as close to winning as possible. Winning a seat in a district or coming close to winning a seat are both roads to increasing visibility: 
whether a party is motivated to change policy, to promote a pet issue, or to push a likeminded establishment party to change its platform, coming as close to winning as possible is a straightforward manner to call attention to the party's goals. This assumption has its roots in a long line of literature beginning with Leiserson (1968) and continuing through to Laver and Schofield (1990) who argue that - whatever their motivation - parties seek office. ${ }^{6}$ Thus, from a strategic perspective, we argue that parties require some sort of informational signal about the potential of winning a seat within each district (which is conceptually distinct from arguing that they actually expect to win a seat).

Before an election takes place, the potential cost of a seat can be estimated by the necessary (or inclusion) electoral threshold: the minimum share of votes needed in a district in order to have a chance of obtaining a seat (Lijphart, 1999). The electoral threshold is an often referenced measure of district-level permissiveness in an electoral system, and as a result, it is often theorized to be a part of the rational, strategic calculus of parties at the time of making entry decisions: lower thresholds imply lower barriers to electoral success, which can in turn result in lower barriers to entry (Bernauer and Bochsler, 2011; Cox, 1997; Selb and Pituctin, 2010). Electoral thresholds of inclusion have three main determinants: in addition to the electoral formula - which remains constant across districts in a given election - the electoral threshold of inclusion depends on the number of seats being allocated in a district and on the number of parties competing for those seats (Ruiz-Rufino, 2007).

We argue, then, that one important informational source for parties that varies at the district level should be the cost of winning a seat in the previous election. This lagged value is readily calculable from past election results and should form parties' expectations about outcomes in the current election. As this cost increases, parties can expect to have a harder time crossing the seat-winning threshold, which, as we have argued, is a fundamental driving force for political parties in electoral competition. Where cost is low, parties should perceive

${ }^{6}$ A more recent review argues that although parties are motivated by different incentives, "it is almost always better to be in office than not" (Müller and Strom, 1999, p. 6). 
an opportunity to very efficiently translate their vote share into one or multiple seats.

H3: As the lagged cost of winning a seat (in votes) in a district increases, selectively entering parties should be less likely to enter that district.

The cost of winning a seat could, however, be relatively low for different reasons. It might be that a relatively small supply of parties are simply weak performers with the voters in that district. But it might also be the case that a relatively large supply of parties have simply fractured the voting public's support into several small constituencies. While seat cost might be low in the latter scenario, it is also the case that the supply side of the electoral market is crowded or over saturated with offerings (Ruiz-Rufino, 2007). Here we would expect selectively entering parties to be less willing to enter the fray and, thus, we control in the analysis that follows for crowdedness in party offerings to voters.

H4: As the lagged crowdedness - or number - of parties in a district increases, selectively entering parties should be less likely to enter that district.

Turning now to the demand side, Cox (1997) likened elections to markets and posited an equilibrium concept that balances both the supply of and demand for party offerings. This equilibrium point is structured by the well-known psychological and mechanical effects of party competition articulated by Duverger (1954): a given set of electoral rules governs the mechanical translation of votes into seats and voters - not wanting to waste their votes on nonviable parties - strategically abandon parties that have entered in excess of this equilibrium. When this equilibrium point is exceeded and a larger number of parties net substantial vote shares, then the electoral market has failed (Lago and Martinez, 2010): many voters have cast ballots that, by virtue of going toward nonviable contenders, will not be included in the mechanical translation of votes into seats. By persistently casting ballots for nonviable parties, voters are, in a sense, giving voice to their dissatisfaction with current party offerings (Hirschman, 1970). 
When selectively entering parties observe electoral market failures, they see a set of voters whose support should be comparatively easy to win (especially vis-à-vis voters who have settled into established patterns of support for consistently seat-winning parties). Given that extant parties have been unable to mobilize support in this non-coordinating section of the district's electorate, the door remains open for a selectively entering party to offer a new option on the menu of party labels. New potential entrants do not have to "steal" votes from already winning parties; rather, they just have to tie up the losing parties' loose ends. In an attempt to capitalize on voter dissatisfaction, then, selectively entering parties will enter districts where there has been a breakdown in voter coordination around a viable set of party offerings. As we discuss in more detail in our data section below, we focus on the amount of hopeless votes - that is, the number of votes going to second and lower losers - as a share of total district votes to capture coordination failures.

H5: As the lagged number of hopeless votes in a district increases, selectively entering parties should be more likely to enter that district.

Similarly, volatility - or fluctuation - in voter support across party offerings is another signal that the preferences of a district's electorate might be unsettled or mutable (Powell and Tucker, 2014; Roberts and Wibbels, 1999). Here again, potential entrants observe a set of voters whose support should be relatively easy to mobilize relative to those voters who consistently cast ballots for the same parties repeatedly (that is, voters expressing nonvolatile preferences). Where substantial swathes of voters are willing to change their partisan allegiances between elections, then selectively entering parties should have a comparably easier time garnering votes in such a district.

H6: As lagged electoral volatility in a district increases, selectively entering parties should be more likely to enter that district. 


\subsection{Controlling for Ideology and Demographics}

A complete theoretical story of selective party entry will also take into consideration several ideological and sociodemographic factors. Political parties of, say, the ideological left will not generally choose to enter right-leaning districts when they must make selective entry choices. More centrist parties might tend to avoid those districts where many extreme parties are winning substantial vote shares and parties whose platforms typically appeal to workingclass Protestants will not selectively target districts populated mainly by wealthy Catholics. These are just a few of many potential examples of how ideology and social demographics influence selective party entry. But they point to a difficult problem in modeling this phenomenon: individual parties will prioritize different aspects of the ideological and social milieu in different ways and, while extreme-minded voters, for example, might appeal to one party, they may well repel another. These party-by-party idiosyncrasies make it difficult if perhaps not impossible - to deduce general theoretical principles that would apply to all selectively entering parties uniformly. Our approach is to take ideology and demographics seriously, but to let the multi-level modeling approach allow for party-by-party differences without trying to force a unified theoretical framework onto the data.

Beginning with ideology, we identify two potentially salient aspects of district-level ideology and allow each of these aspects to differentially influence the probability of entry for each individual party. These aspects are: the overall level of ideological polarization in extant major party offerings at the district level and the weighted mean position (or center of gravity) of extant parties. We argue that different types of parties will be variably drawn toward - or repelled by - one or the other of these indicators. In highly polarized districts, for example, the center of the ideological distribution is comparatively vacant; thus, more ideologically moderate parties may have incentive to target these districts in order to position themselves in empty areas of the distribution (Budge, 1994; Downs, 1957). As the ideological center of gravity moves to the right, parties of the right should be more inclined to enter these districts while parties of the left should be more likely to stay out. 
Moving on to sociodemographics, we identify three salient determinants of vote choice at the level of the individual survey respondent: income, education level, and the ruralurban divide. These three indicators have been productively employed in recent analyses of district-level election outcomes and have the advantage of being measured in each of our countries included in the analysis (whereas, for example, ethnicity and language were not). ${ }^{7}$ Sociodemographic variables should matter for entry, as indicated by a long strain of scholarship on party competition in both the comparative and American contexts, which demonstrates that different-looking groups of voters tend to respond very differently the same set of policy messages from political parties. To the degree, then, that a political party's campaign platform resonates with a certain demographic, the prevalence of that demographic at the district level should incentive the party to selectively enter that district (and forgo entering some other district where the demographic is less prevalent). We will control for each of these sociodemographic indicators in the analysis that follows in order to more completely model the full set of concerns harbored by political elites in determining where they should field their candidates on election day.

\section{DATA AND MEASUREMENT}

We have compiled a database focusing on seven European democracies that rely on proportional representation electoral rules. These seven countries and time periods are Austria (1949-2008), the Czech Republic (1996-2006), Finland (1983-2007), Poland (1992-2007), Portugal (1975-2005), Romania (1992-2004) and Spain (1977-2008) ${ }^{8}$ and all were selected for both theoretical and empirical reasons. Theoretically, multimember systems tend to rely

7 This data limitation is admittedly a shortcoming of our approach. However, as the results of the empirical analysis will indicate, the roles of strategy and space tend to overwhelm the roles of demographic controls in predicting party entry. The future introduction of better ethnic and language data at the districtlevel across multiple countries would allow for a productive follow-on project.

8 These time periods are defined by overlaps in data across the three sources. 
on both fixed constituency boundaries and a fixed number of constituencies (accounting for fluctuation in population size by raising or lowering individual magnitudes, rather than by redrawing boundaries). For the purposes of our research design, this guarantees that parties are not having to make entry decisions by evaluating districts with mutable boundaries or entirely new districts with no electoral history. The creation of new districts and the redrawing of district boundaries are both much more common in single-member district systems and are exceedingly difficult to account for empirically in large- $N$, cross-national research.

Also on the theoretical front, our selection of large-magnitude proportional representation cases should allow us to treat a party's set of entry decisions across the country as emerging from a centralized, top-down party decision making process. That is to say, parties tend to be much more centrally organized in large-magnitude proportional representation systems, thereby allowing us to treat them as more-or-less unitary actors. We want to be able to model a party's selective entry decisions across all districts in the country. If the party's organization was highly decentralized (as it often is in single-member district systems), then it would be difficult for us to make the theoretical claim that the same political actor is evaluating all districts across the country.

Finally, this selection of large-magnitude proportional representation cases should provide for us a very difficult laboratory in which to return support for our geography hypotheses $H 1$ and H2. Geography-based election considerations on the part of party elites are typically thought to be more salient in single-member district systems rather than in multimember systems. In countries of the latter variety, districts tend to be much larger and fewer, making selective entry of a subset of these districts less contingent on geographical considerations. If we can find evidence of geography's role in party's entry decisions in these eight test cases, then we will have crossed a substantial validity threshold for our argument. ${ }^{9}$

From an empirical standpoint, these countries sit at the nexus of several important

9 Additionally, related to our arguments' scope conditions, this selection of seven cases draws from Western, Eastern, Northern, and Southern Europe and across very old and relatively new democracies alike. 
databases for the field of comparative electoral studies, which will allow us to draw on an atypically rich set of district- and country-level covariates. Specifically, each of these eight countries are covered by the Comparative Study of Electoral Systems survey repository (CSES, 2014), the Global Elections Database of district-level vote and seat allocations across all political parties that contested a given election (Brancati, 2014), and the Comparative Manifestos Project (Volkens et al., 2013) which will allow us to track the ideological positions of at least the more major parties in each political system.

\subsection{Operationalizing the Main Explanatory Variables}

Using election data from Brancati (2014), we are able to construct our outcome variable: whether or not a party entered a previously uncontested district in a given election. ${ }^{10}$ Our goal is to understand the mechanisms behind party entry, rather than the mechanisms behind party reentry, so we focus on districts where a party had yet to field candidates. ${ }^{11}$ Accordingly, we define entry $y_{p d e}=1$ if party $p$ obtained a positive vote share in district $d$ in election $e$, and received no votes in election $e-1$. We define entrypde $=0$ for those districts where the party received no votes. We work from the fundamental assumption that, if a party stood for election in a given district, then it received at least one vote in the district. This is not a terribly heroic assumption, given the fact that it would require very few resources for a party to net one vote in any given electoral competition (indeed, we might expect that the candidate who stood in the competition would at least vote for herself or himself). We only include party-district observations for a given party on elections in which the party enters

\footnotetext{
10 Across the seven countries, we are tracking 450 separate parties (each of which is often observed across multiple election periods).

11 This also allows us to hold previous electoral performance in a given district constant by design.
} 
at least one district yet fails to enter every district. ${ }^{12,13}$

To evaluate $H 1$ through $H 6$, we require data along five explanatory variables. The first is geographic proximity. To build our measure of proximity, we collected spatial contiguity (or adjacency) data for all 239 electoral districts included in our sample. For each party, we constructed a spatial contiguity network using immediate neighbors, defined as districts that share a boundary. Treating each district as a node in this network, we then calculated the geodesic distance (i.e. the length of the shortest path) between each district and the closest other district in which a party has entered. This measure allows us to effectively control for differences in country and district sizes. ${ }^{14}$ Calculating proximities specific to each individual party is key here, as our theory posits a connection between a party's decision to enter a given district and the proximity of that district to the existing machinery developed by that specific party to mobilize voters and win elections. So while the strategic incentive of, say, seat cost will be set at the district level and common to all parties, whether or not that district is "proximate" to any given party's additional entry points will vary. To account for differences in the number of districts across countries, we then standardize these geodesics within country.

Second, in order to measure the cost of winning a seat in a district, we calculate the lagged seat cost of the cheapest seat "bought" in that district. Our measure of seat cost is given

12 This ensures that we are not modeling the "selective" entry decisions of parties that entered districts uniformly, which we think represents a different type of decision calculus - namely the decision to be a "national party" and contest all districts accordingly rather than an aggregation of many dozens - or many hundreds - of individual yes-no decisions.

13 Our sampling strategy results in the inclusion of a broad selection of "types" of parties, such as new, niche, small, mainstream, leftist, rightist, etc. On balance, selectively entering parties have relatively targeted scopes, including ideologically extreme, ethnic, and special-interest parties. However, and especially during earlier periods in our sample, we also capture parties that would over time become larger, more national political actors. For a more detailed discussion of the types of parties in our sample, see Appendix C.

14 Our results are essentially robust to an alternative operationalization in kilometers between district centroids; see the discussion of robustness checks below. 
by the "mean threshold of minimal representation" (Taagepera, 2007) - the vote share at which a party has a 50-50 chance of winning one seat. We use the arithmetic mean between the thresholds of inclusion and exclusion in a D'Hondt system as a comparable means of capturing this effective barrier to electoral success (Lijphart, 1999; Taagepera, 2007), given by $\frac{1}{2}\left(\frac{1}{M+p+1}+\frac{1}{M+1}\right)$ - where $M$ is the district magnitude and $p$ is the number of parties competing in the district. This expression captures the idea that the number of votes needed to win a seat in a district depends not only on the number of seats "for sale", but also on the raw number of parties competing for a set of seats. It also reflects the idea that cheapest seat in the district is not always the seat won by the smallest seat-winning party. Imagine a multimember District A. Perhaps the smallest seat-winning party in District A won only one seat, but won it soundly. Suppose that the largest seat-winning party in District A won five seats, but just barely cleared the threshold to win the fifth seat. It is this number of votes needed to gain that last seat that a potential entrant into the district should be evaluating.

Third, we measure the extent of lagged district-level crowdedness by using the effective number of parties statistic developed by Laakso and Taagepera (1979) and subsequently applied in most cross-national work on elections. The measure counts the number of party offerings in the previous election in a district and weighs them by the vote shares they received in that election. This weighting is important because it differentiates between highly fractionalized (or cluttered) districts versus highly consolidated districts with a handful of large party offerings and many clearly nonviable contenders. It also avoids a potential multicollinearity problem with the raw count $p$ term in our calculation for seat cost.

Fourth, we measure voter coordination using the lagged share of hopeless votes - that is, the votes that go to parties that obtained vote-shares less than or equal to that of the second loser. ${ }^{15}$ Our expectation is that as the number of hopeless votes increase, the district should

\footnotetext{
${ }^{15}$ As discussed by Crisp, Olivella and Potter (2012), this measure has some advantages over the more classic "SF ratio" proposed by Cox (1997) because it takes into account the full distribution of voter coordination failure across party offerings rather than focusing on the narrow number of votes.
} 
appear to be a more receptive environment for selectively entering parties. And fifth, as is common in the elections literature, we measure lagged election volatility using the Pedersen Index (defined by $\frac{1}{2} \sum_{p}\left|v_{p, e}-v_{p, e-1}\right|$, where $v_{p, e}$ is party $p$ 's vote share in election $e$ ) calculated using the vote shares of extant parties (Powell and Tucker, 2014).

\subsection{Accounting for Ideology and Demographics}

We now describe our ideological and sociodemographic variables. As noted above, we have no clear systemic or uniform expectations about the performance of these variables across all parties; we do, however, believe that they contribute to a necessarily rich backdrop against which we evaluate our main theoretical claims articulated in $H 1$ through $H 6$. In particular, we will demonstrate in the course of the analysis how these ideological variables impact the propensity to selectively enter a district on a party-by-party basis.

For our ideological variables, we use party manifesto codings from the Comparative Manifestos Project. ${ }^{16}$ First, for each of the CMP-coded major parties that ran in a given district, we multiplied their left-right rile positions by their vote shares and summed across all of these values, thereby constructing an ideological center-of-mass or mean ideological position indicator. ${ }^{17}$ This measure provides a picture of the distribution of party ideologies in the district, contingent upon their electoral size. ${ }^{18}$ We also calculate the overall level of ideologi-

16 An alternative approach would be to try to leverage the individual self-reported survey response ideologies of voters from the CSES database. While we do use the CSES database for demographic controls (see below), we are worried about these self-reported ideology scores being representative at the district level. Instead, we opt for the more objectively coded manifesto scores and interact these with prior election outcomes at the district level as described in the text.

17 We acknowledge that the CMP does not included ideological codings for all parties - no matter how electorally small - that might have contested the district. However, the data tend to cover several major parties in each country and these parties usually account for over $80 \%$ of district's vote shares, which we think allows us to capture at least a plausible snapshot of each district's ideological mass of the party offerings.

18 It is important to point out that even though CMP scores are coded at the national level, our measures of mean ideological position, polarization, and extremism can all assume variable values across districts for 
cal polarization in extant major party offerings at the district level; the polarization of these parties is given by the weighted average of party position deviations from the mean position in the district, using each party's vote share in the district as weights.

Our set of demographic controls includes district-level median income, median education level and the "ruralness" of each district. These demographic measures were calculated based on self-reported characteristics from all respondents in a district across waves of the CSES survey (CSES, 2014). We focus on these three attributes as they were readily available across our set of country-elections and because prior theoretical work has focused on these as being salient determinants of party-specific support patterns (Stoll, 2008). ${ }^{19}$ For each electoral district we obtain one time-invariant measure of median income, median education, and the percentage of the population living rurally.

Finally, we control for two additional variables at the party level: first, the number of prior elections in which a party has participated up until the current election and, second, the lagged overall share of districts a party entered in the prior election. We call the prior variable experience and the latter market penetration and have theoretical reasons for including both in the analysis that follows. For example, the strategic effects described above might be expected to vary over the course of a party's life cycle. Newer or resource-strapped parties might be prone toward mistakes in entering districts strategically, which might weaken the support for $H 1$ through $H 6$ among this subset of parties. The extent of prior market penetration is included in the model because it somewhat mechanically influences the extent of entry in the current election; that is to say, greater prior market penetration should systemeither (or both) of two reasons: first, not all parties the CMP codes will contest all districts; and, second, these parties will receive varying levels of electoral support across districts.

${ }^{19}$ Due to pervasive missingness and homogeneity for this particular subset of countries, we were unable to include data for ethnicity and language. Additionally, respondents across multiple waves of the survey were pooled inside the same districts, giving us greater statistical leverage in describing the district's demographic traits, but sacrificing over-time variation in these traits. In general, as district-level demographics change slowly, we believe this is a justifiable approach. 
atically drive up a party's probability of entering any given district in the current election because it is entering more districts overall. We now turn to a description of our empirical model and discuss our findings.

\section{EMPIRICAL MODEL AND RESULTS}

We are interested in modeling the entry decisions made by selectively entering parties. More specifically, we want to evaluate whether geographic and strategic considerations play a role in the district-by-district, party-level decisions to contest an election. Since these are binary decisions, we model our outcome variable using a binomial model that makes the probability of entry a function of district-level strategic and geographic covariates, in an effort to determine their effect on decisions made by selectively entering parties.

Our data consists of observations that are nested at different, theoretically relevant grouping levels. For instance, we have multiple observations of the same party (both over time and, in the same election, across districts), of the same country (across multiple elections) and of the same district (as it is assessed by different parties during one election and over time). It is important to account for the grouping structures that can result in data dependencies, as ignoring them can result in incorrect inferences regarding the certainty with which we can estimate the effects we are interested in. Furthermore, as our preceding discussion makes clear, a few of our variables vary at different levels: while the cost of a seat varies at the district-election level, the number of elections contested remains constant for every party in any given election. Accordingly, our binomial model includes random intercepts by party, country and unique combinations of district-elections. This allows us to both account for the main sources of dependencies in our data, while helping us evaluate effects at the correct level of variation (by making the intercepts themselves functions of the right covariates).

In addition, and to account for the fact that some of our effects are expected to vary by party, our model also includes random slope (or effect) coefficients for a district's ideological and demographic composition. In general, the non-strategic conditions that may attract a 
party may, in turn, repel another, and the degree to which this is the case depends on partylevel information (e.g. each party's ideological position) that is generally available only for a very small subset of the parties we include in our dataset. Thus, the random coefficient model constitutes the most flexible and a priori unbiased approach to exploring the effects of these covariates as they vary by party.

More formally, we assume each observed entry decision $y_{p d e}$ is drawn from a Bernoulli distribution, and define the probability that a party $p$ enters district $d$ during election $e$ to be a function of geographic proximity (to the nearest other district entered by $p$ ), a random intercept by party $\xi_{p}$, a random intercept by country $\xi_{c}$, and a random intercept by districtelection, $\xi_{d e}$ (in addition to our controls). In turn, $\xi_{d e}$ is drawn from a Normal distribution centered around mean $\mu_{d e}$, defined as a function of (lagged measures of) seat cost, electoral market crowdedness, hopeless votes and voter volatility - each of which is also interacted with distance. These interactions allow us to evaluate the conditional nature of $H 2$. Finally, $\mu_{d e}$ is also defined to be a function of the ideology, polarization and demographic characteristics of a district - the effects of which are expected to vary by party, and which are modeled as being drawn from Normal distributions with zero means and variances to be estimated. Thus, we define the model of a party's district-entry decision in an election as:

$$
\begin{aligned}
y_{p d e} \sim \operatorname{Bernoulli}\left(\pi_{p d e}\right) \\
\operatorname{logit}\left(\pi_{p d e}\right)=\alpha+\xi_{c}+\xi_{d e}+\beta_{1} \text { distance }_{p d e}+\boldsymbol{\beta}_{2} \mathbf{X}_{p d e} \\
\xi_{d e} \sim \mathrm{N}\left(\mu_{d e}, \sigma_{d e}\right) \\
\mu_{d e}=\boldsymbol{\beta}_{2} \mathbf{X}_{d e-1}+\boldsymbol{\beta}_{3}\left(\mathbf{X}_{d e-1} \times \text { distance }_{p d e}\right) \\
\quad+\xi_{1 p} \text { ideology }_{d e-1}+\xi_{2 p} \text { polarization }_{d e-1} \\
\quad+\xi_{3 p} \text { income }_{d e-1}+\xi_{4 p} \text { education }_{d e-1} \\
\quad+\xi_{5 p} \text { rural }_{d e-1} \\
\xi_{i p} \sim \mathrm{N}\left(0, \sigma_{i}\right) \quad \text { for } i \in 1, \ldots, 5
\end{aligned}
$$


where $\alpha, \beta, \boldsymbol{\beta}$. are scalars and vectors of non-random coefficients; $\xi$. are the country, districtelection and party-level random intercept and slopes; and the $\sigma$. parameters are ancillary variability parameters for the random effects. In turn, $\mathbf{X}_{p d e}$ and $\mathbf{X}_{d e}$ are linear predictor matrices, which include control variables and some district-level predictors, respectively. After standardizing all continuous variables for numerical stability purposes, we use maximum likelihood methods to estimate the parameters in our model and report our results in Table B1 of the appendix, which also contains summary statistics of our untransformed variables (in Table A1) to facilitate the interpretations that follow. ${ }^{20}$

\subsection{Results}

In interpreting our results, ${ }^{21}$ we adopt a strategy that builds on the logic of "average predictive comparisons" developed by Gelman and Hill 2007, pp. 101-104;466, ${ }^{22}$ incorporating

${ }^{20}$ We use version 1.1-6 of the lme4 package in $\mathrm{R}$ to estimate our model. The code and data required to replicate our estimation results and all graphs included in the discussion are available at *.edu.

${ }^{21}$ Our estimated model fits the data very well. With a deviance of 15496.8 on 28523 degrees of freedom, the model's performance is indistinguishable from that of the saturated model. Furthermore, the area under the ROC curve for our model is around 0.95 - evidence that our model is very good at discriminating between attractive and unattractive districts.

22 Teasing out the effect of each of our covariates on the probability of entry can be difficult - particularly given the multiple levels at which we expect these effects to operate. Additionally, the non-linear nature of our model makes it hard to calculate marginal and conditional quantities of interest, such as the effect of increasing a variable over some set range of values. To address these issues, Gelman and Hill propose using "average predictive comparisons" for each covariate $x$ - that is, for a dataset with $n$ observations, the mean across $n$ differences in predicted probabilities under two covariate profiles that differ only in terms of the value of $x$, and which let all other covariates take on their $n_{t h}$ observed values. The approach, advocated under various names in different literatures (see, for instance, Hanmer and Ozan Kalkan, 2013; Long, 1997), makes interpretation of ceteris paribus effects embedded in non-linear models less sensitive to the choice of covariate values at which other variables are held constant. In addition, focusing on predicted quantities of interest (in our case, the probability of entry) makes interpretation much more intuitive and less dependent on the complicated structure of the model's specification. 
inferential uncertainty for every predicted value. Instead of calculating the average difference between two predicted probabilities (under high and low values of a given covariate, for instance) across all observations for a given variable $X$, we sample predicted probabilities of entry for a range of values of $X$ while holding all other covariates at their observed values, using the estimated multivariate sampling distribution of our non-random parameters. ${ }^{23}$ Figure 1 shows a summary of these sampled predicted probabilities (viz. the median predicted probability along with $90 \%$ confidence bands) as we let each of our main variables vary over their observed range.

\section{[ Insert Figure 1 About Here ]}

Overall, our hypotheses are largely supported by the data. Each panel in Figure 1 contains two curves of predicted probabilities - one for the probability of entering a district that is contiguous to a district that is being contested by the party (solid line), and another for the probability of entering a district that is about 1 standard deviation away from a district contested by the party (dashed line). ${ }^{24}$ They are, therefore, the effects of each strategic covariate conditional of those two proximity conditions.

The panels are designed to convey three main pieces of information. First, the gap between the two predicted probability curves indicates the magnitude of the proximity effect: a separation between the two curves indicates that the probability of entry is different for districts that are close to other entered districts and districts that are far from the nearest

${ }^{23}$ More specifically, we start by taking 500 samples from the estimated multivariate Normal sampling distribution of all $\mu, \beta$ and $\boldsymbol{\beta}$. parameters in our model. For each value of $X=x$ at which a prediction is desired, we use each parameter sample to obtain a set of $n$ predicted probabilities - thereby producing an $n \times 500$ matrix $\mathbf{P}_{x}$. For each sample, we take the average prediction across all observations (i.e. across all rows), leaving us with a row vector of 500 average predictions $\mathbf{p}_{x}$, of which we keep the $5^{\text {th }}, 50^{\text {th }}$ and $95^{\text {th }}$ percentiles. For each value $x$, these percentiles are the quantities plotted in our Figure 1.

${ }^{24}$ Recall that our measure of distance between any two districts consists of the standardized number of districts between them. 
district entered by the party. Second, the slopes of each curve indicate the direction and strength of the (conditional) effect of the corresponding explanatory variable (as indicated by the panel titles) on the probability of entry. Thus, a curve that falls rapidly would indicate a strong negative effect of the corresponding covariate on the probability that a party enters the district. Finally, a difference in the slopes of the two curves within each panel indicates an interaction effect between proximity and the corresponding strategic covariate.

Considering these pieces of information, the results depicted in Figure 1 suggest that among all our predictors, proximity has the largest, most consistent effect on the probability of entry, and that this effect is consistent with $H 1$. As evidenced by the fact that the dashed line is almost always below the solid line in all panels (and is, often times, much lower than it), our model suggests that parties are much more likely to enter districts that are contiguous to other districts they are contesting than to enter more distal districts. Only in extremely "expensive" or extremely crowded districts - where the probability of entry is predicted to be effectively zero - does this effect disappear. Indeed, and with the exception of districts where seat cost is very low, the baseline probability of entry in distal districts is so small that even statistically discernible effects on the probability of entry become, practically speaking, negligible. In contrast, an increase in proximity to a previously entered district dramatically increases the probability of entry, to the point where entering a contiguous district becomes, under the right strategic conditions, extremely likely.

The model not only supports our intuitions regarding the overall effect of proximity $(H 1)$ - it also largely supports the idea that relevant strategic effects depend on distance from other districts $(H 2)$ in which a party vies for election. Specifically, proximity modifies the impact of the three strategic variables that have a discernible effect on the probability of entry (viz. seat cost, party crowdedness and hopeless votes). Previous district crowdedness, for instance, has a negative effect on the probability of entering districts close to other entered districts, while having the opposite effect on far-away districts. Even more notable, proximate districts seem to be more sensitive to changes across all seat costs, while distal 
districts appear much more reactive to changes in the low end of the seat cost spectrum. This suggests that, for two districts that differ with respect to how far they are to other contested districts (but are similar with respect to how much a seat costs), it only takes a small increase in the seat cost of the distal district to reduce the probability a party enters it, whereas much greater costs are needed to deter entry in a proximate district. Overall, then, geography does seem to affect the way parties rely on strategic considerations when making entry decisions.

Consistent with $H 3$, the anticipated cost of a seat is expected to reduce the probability of entry in a proximate district by roughly 66 percentage points - from almost about $68 \%$ chance of entry (at minimal costs) to about $2 \%$ chance of entry (at maximal costs). An equal change in the seat cost in a distal district (i.e. a district that is about 4 districts away from the nearest entered district) reduces the probability of entry by about 15 percentage points (viz. from a $15 \%$ chance to an almost $0 \%$ percent chance) - another substantial reduction. The appeal of a proximate district is also expected to decrease the more crowded it becomes (as hypothesized in $H 4$ ), once again taking the predicted percent probability from around $50 \%$ to a low of about $100 \%$, as our measure of crowdedness (i.e. the effective number of parties) spans its observed range. In distal districts, however, the effect becomes statistically indiscernible from zero. Substantively speaking, this suggests that parties pay attention to what their competitors are doing during election campaigns, and they are especially cognizant of election dynamics in proximate areas of the country.

In turn, and as suggested by $H 5$, the data also seem to (weakly) support the idea that potential entrants find value in a lack of electoral coordination, as increasing the amount of hopeless votes cast in a district makes it slightly more appealing for parties in the next election. More specifically, our model suggests that going from almost perfect coordination to $78 \%$ hopeless votes increases the percent probability of entering a district by about 17 percentage points - from roughly a $38 \%$ chance to about a $55 \%$ chance of entry. Contrary to our expectations, however, there does not appear to be enough evidence to suggest that 
lack of voter satisfaction with extant party alternatives, as expressed by electoral volatility, has any effect on a district's entry appeal (H6). In fact, the effect appears to be negative, though the size of the effect is so small that it fails to achieve statistical significance. As we elaborate upon further in the next section, we think this points to a fascinating disjuncture in the supply and demand sides of the electoral market.

Our controls display discernible effects, with every 10 (or one standard deviation) additional election of experience reducing the odds of entry by about $45 \%$, and every additional 30 percentage points (or one standard deviation) of electoral market penetration increasing the odds of entry in any given district by about 19\%. Finally, recall that ideological and demographic controls were modeled as having different (random) effects for each party in our sample. Among these controls with party-dependent effects, district ideology and polarization seem to be the most salient determinants of entry, with changes in the odds of entry as large as $-32.34 \%$ and $28 \%$ (respectively) for every additional standard-deviation increase, and a substantial amount of variability (with a $\sigma_{1 p}=1.395$, and $\sigma_{2 p}=1.353$ ). Our results also suggest that demographic characteristics of districts have little independent effect on the decision to enter a district, with a maximum estimated change of about $-2 \%$ (for a standarddeviation increase in the ruralness of a district) and very small variances in the effects across parties. ${ }^{25}$ This relatively small effect of demographic characteristics is, once again, evidence of a disjuncture between the supply and demand of political representation we alluded to before: if parties were paying close attention to the "needs" of voters as evidenced by the balloting preferences and sociodemographic characteristics, we would expect these effects to be stronger. As it is, parties appear to make entry decisions more in line with what they can do given other parties' strategies, rather than what voters might want them to do.

\footnotetext{
${ }^{25}$ Figures B1 and B2 in the appendix display the distribution of these party-level effects across all parties. A fuller discussion of how to interpret these effects can also be found in the Appendix.
} 


\subsection{Robustness Checks}

To evaluate the robustness of our results to some of our most important specification decisions, we consider two potential sources of bias in our results. First, it is possible that our results are mainly driven by the countries we include in our sample. In trying to accommodate data needs and availability, our resulting sample of party entry decisions is not well balanced: there are, for instance, many more observations for Spain than for any other country; similarly, our observations for Austria cover a much longer time period than that covered by the observations coming from any other country. Thus, we produce the Cook's distances (i.e. an overall measure of how much our estimated coefficients change as a result of dropping certain observations) that result from dropping, in turn, the observations that belong to each country. Although (as expected) these measures are higher for Spain (at 0.224), no value is high enough to support the claim that our main results are being driven by observations from any given country. ${ }^{26}$

Second, it could be argued that our results confound two very different scenarios: situations in which parties enter an election for the first time in history, on the one hand, and situations in which parties have participated in previous elections, and are attempting to expand their electoral reach, on the other. Although our main model controls for electoral party experience, it is possible that some of the effects of geographic and strategic variables depend on which scenario we are considering. To evaluate how robust our findings are to these different conditions, we reestimate our model using a subset of "first entry decisions" (for first-time party entrants) and another subset of "subsequent entry decisions" (for parties that have some electoral experience in different districts). The results of estimating these models - which are presented in columns 2 and 3 of Appendix B, Table B1, respectively support the idea that proximity to other entered districts is the strongest determinant of entry decisions for parties in either condition, and that strategic factors have similar effects

26 The Cook's distances are as follows: Austria 0.002; Czech Republic 0.037; Finland 0.005; Poland 0.02; Portugal 0.001; Romania 0.00001; and Spain 0.224. 
under both scenarios, though crowdedness and hopeless votes seem to be better determinants of first-time entry, and seat cost loses some of its strength when considering subsequent entry.

Finally, we implement an alternative operationalization of district "proximity" using the (country-standardized) distance, in kilometers, between the district centroids, and reestimate our full model. The results, which are presented in column 4 of Table B1, are in line with our main findings, with two exceptions. ${ }^{27}$ First, the overall effect of proximity (thus measured) appears to be smaller in magnitude. Second, the effect of the amount of hopeless votes (which was small but statistically significant in our main model) is no longer discernible from zero. As we discuss below, this is in line with our interpretation of the findings conveyed by our main model, and points to an important asymmetry between demand-side and supply-side strategic incentives for entry.

\section{DISCUSSION}

We began by pointing out an important empirical gap in our understanding of strategic party entry and, furthermore, by demonstrating that this gap has left us without an explanation for important empirical variation at the subnational level. Investigating the entry decisions of parties at the aggregated national level obscures a vitally important additional strategic calculation that these parties must conduct: how do selectively entering parties decide on a subset of all possible electoral constituencies in which to enter? Prior to this study, the question of selective entry had yet to be addressed at the district level in a truly comparative fashion. In those terms, this paper marks the first empirical effort to frame district-by-district entry decisions in a hierarchical data structure that directly models the implicit tradeoffs these selectively entering parties face in deciding where to field candidates or party lists

\footnotetext{
27 While our original operationalization relies on contiguity matrices (which are easily constructed even without access to GIS-compatible maps), this approach requires access to projected, vectorized maps. This constraint forces us to reduce our sample considerably (by about half) and focus on 4 countries: Finland, Portugal, Romania and Spain.
} 
under various social and electoral conditions.

After examining the results of our analysis, three contributions to our current understanding of party competition should be apparent. First, supply-side strategic electoral considerations are important determinants of a party's decision to enter an electoral district. Simply put, parties care about the actions of other parties: they enter districts where they believe their competitors are vulnerable in the vote-to-seat translation. It might be argued that finding that electoral thresholds play such a robust role in entry decisions should come as no surprise, as we have known for quite some time that such thresholds succinctly capture the most politically relevant characteristic of electoral systems. But our contribution here is twofold: to model the logics of these entry decisions at the correct level of analysis and to explore the mediating effect of electoral geography.

Indeed, our second - and most important - contribution is supplying evidence that geography matters substantially for parties when evaluating their electoral prospects on a district-by-district basis - both in mediating supply-side strategic considerations and in its own right. As a party considers entering an electoral district in the upcoming election, moving that district closer to a district where it already has some resources on the ground dramatically increases the probability that the party enters there as well. But that is not all. Geographic proximity also prompts parties to pay greater attention to the same sorts of strategic cues they would ignore in more distant districts. Put differently, the logistical difficulties of contesting distant districts is sufficiently concerning for parties in some circumstances that we would expect them to pass up opportunities to field their candidates in potentially amenable districts. To the best of our knowledge, the present study is the first to capture cross-national evidence of this important mediating effect of geography.

Finally, we show that while parties care about the actions of other parties, they do so specifically at the expense of caring about the representational needs of the voters. The effects of previous signals of voters' discontent with extant party offerings are either substantively small (hopeless votes) or virtually nonexistent (vote volatility), regardless of whether or not 
the district in question is geographically proximate. Combine this with our substantively small findings regarding the effect of our demographic and ideological controls on party entry, and we quickly run afoul of the normatively desirable characterization of elections as giving political parties opportunities to respond to the needs of voters. Rather than serving as representational reflections of the electorate - whether in demographic terms as the sociological literature on parties would suggest or in ideological terms as indicated by the spatial modeling literature on elections - selectively entering parties instead act as political entrepreneurs that simply field candidates where the mechanics of elections provide them an opportunity. This entrepreneurial approach to representation forces voters and more established parties to sort the problem out for themselves (Schofield, 2006). By "passing the buck" along to the voters and mainstream parties, selectively entering parties may clutter the decision landscape and pile on complexity in the representational process.

The implications of these results raise three potentially interesting avenues for future work. First, our findings point to clear predictions regarding parties' diffusion across electoral districts over time: employing a more dynamic approach to the research question, we would expect parties' entry decisions to be clustered together in geographical space and then slowly branch out to adjacent districts. This research could, for example, shed new light on the party system nationalization literature by explicitly wrestling with the elite-level population of voters' ballots across space. Secondly, much like the issue of selective party entry, the matter of party exit decisions remains unexplored in the comparative literature. Future studies could evaluate whether the logic of our arguments holds when parties are deciding to leave a previously contested district. Thirdly, future work could test the normatively problematic implications of our findings for representational democracy: how do voters respond in the face of selective party entry when they did not signal their demand for a new ballot offering? How do voters respond when they would prefer new alternatives, but never receive them? Individual-level surveys exploring voters' satisfaction with democracy in the face of selectively entering parties could constitute an interesting update to theories of representation. 


\section{REFERENCES}

Althaus, Scott L. and Todd C. Trautman. 2008. "The Impact of Television Market Size on Voter Turnout in American Elections." American Politics Research 36(6):824-856.

Bernauer, Julian and Daniel Bochsler. 2011. "Electoral Entry and Success of Ethnic Minority Parties in Central and Eastern Europe: A Hierarchical Selection Model." Electoral Studies $30(4): 738-755$.

Blais, André, Romain Lachat, Airo Hino and Pascal Doray-Demers. 2011. "The Mechanical and Psychological Effects of Electoral Systems: A Quasi-Experimental Study." Comparative Political Studies 20(10):1-23.

Brancati, Dawn. 2008. "The Origins and Strengths of Regional Parties." British Journal of Political Science 38(1):135-159.

Brancati, Dawn. 2014. "Global Elections Database." New York: Global Elections Database.

Budge, Ian. 1994. "A New Spatial Theory of Party Competition: Uncertainty, Ideology, and Policy Equilibria Viewed Comparatively and Temporally." British Journal of Political Science 24(4):443-467.

Callander, Steven. 2005. "Electoral Competition in Heterogeneous Districts." Journal of Political Economy 113(5):1116-1145.

Campbell, James E., John R. Alford and Keith Henry. 1984. "Television Markets and Congressional Elections." Legislative Studies Quarterly 9(4):665-678.

Caramani, Daniele. 2000. Elections in Western Europe since 1815: Electoral Results by Constituencies. London: Macmillan Reference.

Carty, R. K. and Munroe Eagles. 1999. "Do Local Campaigns Matter? Campaign Spending, the Local Canvass and Party Support in Canada." Electoral Studies 18:69-87. 
Chernoff, Herman. 1954. "Rational Selection of Decision Functions." Econometrica $22(4): 422-443$.

Chhibber, Pradeep and Ken Kollman. 2004. The Formation of National Party Systems: Federalism and Party Competition in Canada, Great Britain, India, and the United States. New Jersey: Princeton University Press.

Cox, Gary W. 1997. Making Votes Count: Strategic Coordination in the World's Electoral Systems. Cambridge University Press Press.

Crisp, Brian F., Santiago Olivella and Joshua D. Potter. 2012. "Electoral Contexts that Impede Voter Coordination." Electoral Studies 31(1):143-158.

CSES. 2014. "The Comparative Study of Electoral Systems." Online data repository .

Downs, Anthony. 1957. Economic Theory of Voting. Harper and Row.

Duverger, Maurice. 1954. Political Parties: Their Organization and Activity in the Modern State. Wiley \& Songs.

Gelman, Andrew and Jennifer Hill. 2007. Data analysis using regression and multilevel/hierarchical models. Cambridge University Press.

Gimpel, James G., Frances E. Lee and Joshua Kaminski. 2006. "The Political Geography of Campaign Contributions in American Politics." The Journal of Politics 68(3):626-639.

Hanmer, Michael J. and Kerem Ozan Kalkan. 2013. "Behind the Curve: Clarifying the Best Approach to Calculating Predicted Probabilities and Marginal Effects for Limited Dependent Variable Models." American Journal of Political Science 57(1):263-277.

Harmel, Robert and John D. Robertson. 1985. "Formation and Success of New Parties." International Political Science Review 6(4):501-523. 
Hirschman, Albert O. 1970. Exit, Voice, and Loyalty: Responses to Decline in Firms, Organizations, and States. Harvard University Press.

Huckfeldt, Robert and John Sprague. 1992. "Political Parties and Electoral Mobilization: Political Structure, Social Structure, and the Party Canvass." American Political Science Review 86(1):70-86.

Hug, Simon. 2001. Altering Party Systems: Strategic Behavior and the Emergence of New Political Parties in Western Democracies. Ann Arbor: University of Michigan Press.

Jackson, John E. 2002. "A Seemingly Unrelated Regression Model for Analyzing Multiparty Elections." Political Analysis 10(1):49-65.

Johnston, Ron J. and C. A. Hughes. 2008. "Constituency Delimitation and the Unintentional Gerrymander in Brisbane." Australian Geographical Studies 16(2):99-110.

Jones, Mark P. and Scott Mainwaring. 2003. "The Nationalization of Parties and Party Systems: An Empirical Measure and an Application to the Americas." Party Politics 9(2):139-166.

Katz, Jonathan N. and Gary King. 1999. "A Statistical Model for Multiparty Electoral Data." American Political Science Review 93(1):15-32.

Kitschelt, Herbert. 1988. "Left-Libertarian Parties: Explaining Innovation in Competitive Party Systems." World Politics 40(2):194-234.

Laakso, Markku and Rein Taagepera. 1979. "Effective Number of Parties: A Measure with Application to West Europe." Comparative Political Studies 12:3-27.

Lago, Ignacio and Ferran Martinez. 2010. "Why New Parties?" Party Politics online:1-18.

Laver, Michael and Norman Schofield. 1990. Multiparty Government. Oxford University Press. 
Leiserson, Michael. 1968. "Factions and Coalitions in One-Party Japan." American Political Science Review 62(3):770-787.

Lijphart, Arend. 1999. Patterns of Democracy. Yale University Press.

Long, J. Scott. 1997. "Regression Models for Categorical and Limited Dependent Variables." Advanced Quantitative Techniques in the Social Sciences 7.

Meguid, Bonnie. 2005. "Competition Between Unequals: The Role of Mainstream Party Strategy in Niche Party Success." American Political Science Review 99(3):347-359.

Morgenstern, Scott and Javier Vazquez-D'Elia. 2007. "Electoral Laws, Parties, and Party Systems in Latin America." Annual Review of Political Science 10:143-168.

Mudde, Cas. 2007. Populist Radical Right Parties in Europe. Cambridge University Press.

Müller, Wolfgang C. and Kaare Strom, eds. 1999. Policy, Office, or Votes? How Political Parties in Western Europe Make Hard Decisions. Cambridge: Cambridge University Press.

Plott, Charles R. 1973. "Path Independence, Rationality, and Social Choice." Econometrica 41(6):1075-1091.

Powell, Eleanor Neff and Joshua A. Tucker. 2014. "Revisiting Electoral Volatility in PostCommunist Countries: New Data, New Results and New Approaches." British Journal of Political Science 44(01):123-147.

Roberts, Kenneth M. and Erik Wibbels. 1999. "Party Systems and Electoral Volatility in Latin America: A Test of Economic, Institutional, and Structural Explanations." American Political Science Review 93(3):575-590.

Rodden, Jonathan. 2010. "The Geographic Distribution of Political Preferences." Annual Review of Political Science 13:321-340. 
Ruiz-Rufino, Rubén. 2007. "Aggregated Threshold Functions or How to Measure the Performance of an Electoral System." Electoral Studies 26(2):492-502.

Scarrow, Susan. 1994. "The 'Paradox of Enrollment': Assessing the Costs and Benefits of Party Memberships." European Journal of Political Research 25(1):41-60.

Schofield, Norman. 2006. Architects of Political Change. Cambridge University Press.

Selb, Peter and Sandrine Pituctin. 2010. "Methodological Issues in the Study of New Parties' Entry and Electoral Success." Party Politics 16(2):147-170.

Stoll, Heather. 2008. "Social Cleavages and the Number of Parties: How the Measures You Choose Affect the Answers You Get." Comparative Political Studies 41(11):1439-1465.

Taagepera, Rein. 2007. Predicting Party Sizes: The Logic of Simple Electoral Systems. Oxford University Press.

Tavits, Margit. 2012. "Organizing for Success: Party Organizational Strength and Electoral Performance in Postcommunist Europe." The Journal of Politics 74(1):83-97.

Taylor, P. J. and G. Gudgin. 1976. "The Myth of Non-Partisan Cartography: A Study of Electoral Biases in the English Boundary Commission's Redistribution for 1955-1970." Urban Studies 13(13):13-25.

Tobler, W. 1970. "A Computer Movie Simulating Urban Growth in the Detroit Region." Economic Geography 46:234-240.

Volkens, Andrea, Pola Lehmann, Nicolas Merz, Sven Regel and Annika Werner. 2013. "The Manifesto Data Collection." Manifesto Project (MRG/CMP/MARPOR). Version $2013 b$. Berlin. . 


\section{FIGURES}
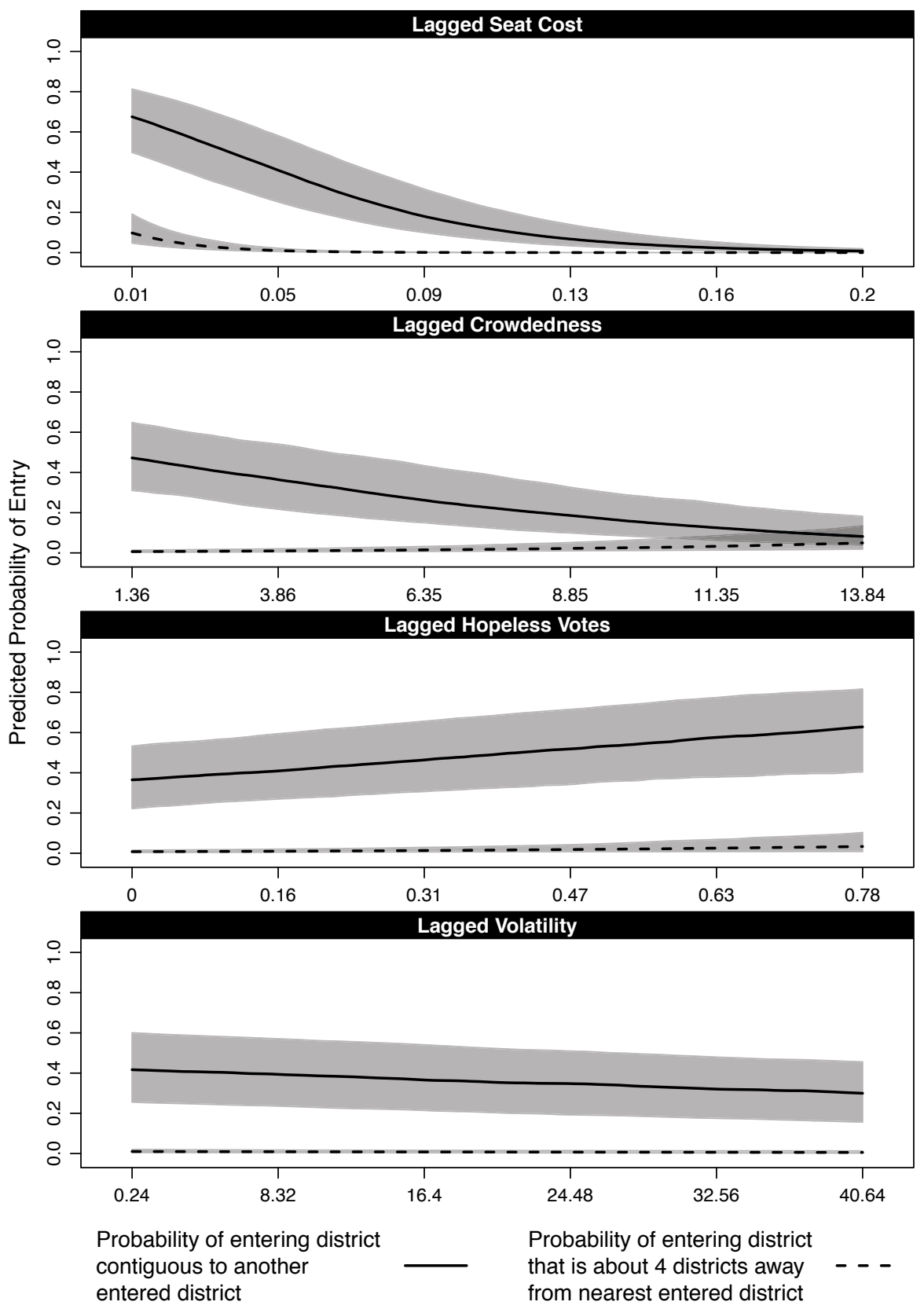

Figure 1. Predicted probabilities of entry for fixed effects (averaged across observed values of remaining covariates), along with $90 \%$ confidence intervals. 